\title{
Evaluating Qualitative Research for Social Work Practitioners
}

\author{
Cynthia A. Lietz \\ Luis E. Zayas
}

\begin{abstract}
In the field of social work, practitioners must remain well informed regarding research advances in their respective areas. Proponents of evidence-based practice expect social workers to engage in practice informed by the best available evidence. Research studies conducted through the lens of qualitative inquiry provide important contributions to the social work knowledge base. In many cases, these studies can represent the best available research regarding emerging problems or application of evidence to diverse populations. Yet, despite the relevance of qualitative research, many social workers receive minimal training regarding qualitative methodology hindering their ability to conduct and evaluate research that uses qualitative methods. The purpose of this article is to provide students and practitioners some orientation regarding qualitative research methods and to highlight potential strategies researchers and consumers of research may use to evaluate the trustworthiness and quality of qualitative research. Specifically, the concept of trustworthiness is defined in the context of qualitative inquiry and questions social work practitioners can ask when evaluating the quality and applicability of a qualitative research study are provided.
\end{abstract}

Keywords: Qualitative, research methods, trustworthiness

\section{INTRODUCTION}

As social workers intervene with individuals, families, and communities, it is critical to remain informed regarding the literature base and research advances specific to one's field of practice. The National Association of Social Workers (NASW)'s Code of Ethics (1999) asserts the importance of engaging in practice informed by prevailing research when it states "social workers should critically examine and keep current with emerging knowledge relevant to social work." Similarly, the Council on Social Education (CSWE) recently identified ten core competencies of social work practice, one of which involves engaging in "research-informed practice and practice-informed research" (Holloway, Black, Hoffman, \& Pierce, 2009, p. 2). Moreover, the evidence-based practice (EBP) movement has increased the expectation that social workers actively seek research findings related to their particular domain of practice (Howard, McMillen, \& Pollio, 2003; Jenson, 2005). Specifically, EBP asserts social workers make decisions guided by research evidence working in conjunction with clinical expertise and client preferences (Gambrill, 2007; Gilgun, 2005; McNeece \& Thyer, 2004).

Although most would agree with the importance of identifying and reading research articles related to one's area of practice, there are many challenges social workers face as they seek to achieve this goal (Adams, Matto, \& LeCroy, 2009). First, social workers are under increased pressure to do more in less time. Caseloads are increasing and budget

Cynthia A. Lietz, Ph.D., and Luis E. Zayas, Ph.D., are Assistant Professors in the School of Social Work at Arizona State University in Phoenix.

Copyright @ 2010 Advances in Social Work Vol. 11 No. 2 (Fall 2010), 188-202 
cuts in many agencies require social workers to serve multiple roles. Additionally, many practitioners do not have access to library databases and other resources that may have been available to them while pursuing their education. Coupled with the challenges of finding the needed time and resources, even once social workers identify current research articles related to their field of practice, many struggle to ascertain the quality and applicability of a particular study to their work.

The purpose of this article is to address the question of quality and applicability as it relates to qualitative research in social work. A growing literature base stemming from qualitative research studies produce findings of relevance to social work practice. However, a recent study reviewing master's level social work syllabi found content regarding qualitative methods was "generally very limited" (Drisko, 2008, p. 89) suggesting many social workers receive limited education about evaluating qualitative methods. To help overcome this limitation, this article seeks to provide social work practitioners some guidance when assessing the methodological quality of studies that employ qualitative methods.

\section{QUALITATIVE METHODOLOGY}

Qualitative research represents a "family of methods" stemming from a variety of traditions (Padgett, 2008 p. 1). Denzin and Lincoln (2008) explain, "qualitative researchers study things in their natural settings, attempting to make sense of, or interpret, phenomena in terms of the meanings people bring to them” (p. 4). Qualitative inquiry developed through a rich history of research seeking contextualized, in-depth descriptions that offer increased understanding.

Although qualitative inquiry is consistent in its naturalistic approach, researchers adopt a variety of perspectives that inform their work. Many qualitative research articles will identify or implicitly embrace a philosophical stance or paradigm to frame their work, such as post-positivist, social constructivist, or critical theory (Creswell \& Miller, 2000; Morrow, 2007). Understanding the perspective used to guide the study will help the reader understand the epistemological position of the researchers and the methods used to answer the research question (Drisko, 1997). For example, post-positivist research seeks methods that are systematic, constructivist research asserts all knowledge is co-constructed thus prioritizing depth over methodological structure, and the critical paradigm calls for collaboration and corroboration with research participants (Creswell \& Miller, 2000). These paradigmatic stances impact the way researchers conceptualize their qualitative studies (Morrow, 2007). Therefore, as Caelli, Ray, and Mill (2003) suggest, "each qualitative approach needs to be evaluated in a manner that is congruent with its epistemological and methodological origins” (p. 7).

Creswell (1998) identifies five qualitative inquiry traditions: ethnography, phenomenology, biography/narrative, grounded theory, and case studies. Others also discuss critical, feminist, and action research (Denzin \& Lincoln, 2008; DePoy, Hartman, \& Haslett, 1999; Olesen, 2000), and new approaches continue to emerge. Many suggest embracing one of these approaches when conceptualizing a qualitative study is one way of enhancing the quality of the project as these frameworks rest on established 
philosophical foundations. Also, certain strategies for rigor are deemed more suitable than others based on the study's approach (Padgett 2008). However, there has been a recent increase in qualitative studies using generalized qualitative methods rather than a specific tradition. Some suggest these generalized studies can produce useful findings when conducted systematically, even if they do not embrace one of the recognized qualitative approaches (Caelli et al., 2003; Patton, 2002).

\section{QUALITATIVE AND QUANTITATIVE RESEARCH: COMMONALITIES AND DIFFERENCES}

Research seeks the development of knowledge derived from empirical evidence. Data are collected and analyzed through procedures that are reported for review and evaluation, an important part of the scientific tradition. Despite these commonalities, there remain some specific differences between quantitative and qualitative research (Frankel, 1999; Lincoln \& Guba, 1985; Rubin \& Babbie, 2010). First, their purposes are often different. Quantitative research often seeks through measurement to test hypotheses, to determine outcomes and to draw generalizable conclusions to a defined population. Qualitative research tends to be interpretivist and seeks to understand a phenomenon in its context in greater depth (Denzin \& Lincoln, 2008; Morrow, 2007). It seeks to elucidate the nature of social practices, relationships, and beliefs along with the meaning of human experiences from the participants' point of view. Generally, qualitative studies differ from quantitative studies in that they are inductive rather than deductive, and they consider experiences within context rather than controlling for variables as in an experiment (Bogdan \& Biklen, 2007; Lincoln \& Guba, 1986). Quantitative studies may administer a standardized instrument to measure a variable with closed-ended items developed and tested for their ability to produce valid and reliable data. On the other hand, qualitative inquiry employs data collection strategies such as indepth interviews, participant observation, and archival reviews (Polkinghorne, 2005). Understanding these differences is the first step in evaluating research articles as it is essential that there is congruency between the purpose of the research and the methods chosen to achieve those aims (Frankel, 1999).

Once practitioners gain some clarity regarding the fundamental commonalities and differences between quantitative and qualitative research, social workers need to develop an understanding regarding how to evaluate the quality of studies conducted within each methodological tradition. Critique is a part of the research tradition. It is expected that researchers conduct their projects through procedures that are presented to the research community allowing readers to draw conclusions from findings that are appropriate considering each study's limitations. In quantitative research, studies are evaluated according to the level of reliability and validity related to the measurement procedures, the internal validity established through the design of the study, and the external validity or the degree to which the sampling procedures allowed for generalizability (Creswell, 2008; Lincoln \& Guba, 1986; Rubin \& Babbie, 2010). In qualitative research, the process for ascertaining the quality of research is quite different according to its varied purposes and methods. The following section describes criteria used to evaluate qualitative 
research along with the strategies used by researchers to increase the quality of their qualitative studies.

\section{EVALUATING QUALITATIVE RESEARCH}

The issue of evaluating qualitative research can prompt a lengthy debate about varied perspectives regarding epistemology and whether the activity of truth finding is even possible (Emden \& Sandelowski, 1998; 1999; Kincheloe, 2001; Whittemore, Chase, \& Mandle, 2001). Although we acknowledge the importance and relevance of this ongoing debate, our purpose here is not to engage in a philosophical discussion regarding ways of knowing, but to instead provide practitioners some practical ways for looking at the quality of qualitative research. We acknowledge there are differences of opinion on these issues. Therefore, we chose to utilize the ideas of Lincoln and Guba (1985) when discussing the topic of evaluating quality. Whittemore, Chase, and Mandle (2001) conclude Lincoln and Guba's (1985) criteria to be the "gold standard" with "staying power" (p. 527). Their conceptualization represents the most cited standards for evaluating qualitative work and provides some practical direction for practitioners.

Lincoln and Guba's (1985) seminal work identified criteria evaluating qualitative research. They suggest that qualitative studies should achieve "trustworthiness;" a study that represents as closely as possible the perspectives of the research participants. Consider that a research team wants to understand the experience of youth who age out of foster care and choose to conduct a series of in-depth interviews with a sample of young adults who identify with this experience. The researchers may have some preconceived ideas regarding what these participants might share. Despite these ideas, the study is trustworthy if steps are taken in the research procedures to ensure the perspectives of these participants are authentically gathered and accurately represented in the findings. Lincoln and Guba (1985) address this by considering four concepts that work together to achieve trustworthiness - credibility, transferability, auditability, and confirmability. These concepts are defined further to provide guidelines practitioners can use when evaluating qualitative studies. A series of strategies researchers can use to enhance the quality of qualitative research are also discussed.

\section{Credibility}

Credibility refers to the degree to which a study's findings represent the meanings of the research participants (Lincoln \& Guba, 1985). Drisko (1997) suggests qualitative "interpretations must be authentic and accurate to the descriptions of the primary participants” (p. 191). Padgett (2008) explains that, to achieve credibility, qualitative research must manage the risk of research reactivity and bias. Research reactivity refers to the potential for the researcher or the study procedures to exert an impact on the participants thereby changing the findings of the study. For example, a researcher interested in family violence may design a study that videotapes family interactions for the purpose of understanding the nature of relationships shaped by aggression. However, the presence of the camera when researching a socially undesirable behavior will likely affect the way families interact. When researchers analyze these tapes, they will observe a family's interaction while being recorded, not a true representation of how that family 
may have behaved if the camera were not present. Research reactivity can also occur based on how researchers develop and ask interview questions, display affirming or nonaffirming non-verbal communication, or even through their degree of participation when engaging in observations. In order to manage this threat, qualitative researchers need to remain aware of how the research procedures may exert an influence on the credibility of the data.

In addition to reactivity, researchers also remain mindful regarding the potential impact of their own bias. Researcher bias involves how researchers' socio-political locations and preconceived ideas may shape the way they design the study and engage in analysis, thereby potentially leading to a misrepresentation of the data (Lietz, Langer, \& Furman, 2006). For example, if a researcher wants to explore client satisfaction with a parent training program, the researcher may conduct a focus group in which participants discuss their experiences. If the researcher has a stake in the outcome, she may be tempted to engage in interviewing that encourages discussion of successful outcomes while failing to attend or draw out comments related to negative impressions of the program. Researcher bias can affect other aspects of a research project beyond data collection. The research question, decisions about research procedures, and the process of data analysis are all influenced to some degree by the experience, knowledge base and standpoint from which one comes to a research project (Horsburgh, 2003).

As qualitative researchers seek to achieve credibility, there are strategies that can be used to manage the threats of research reactivity and bias. To manage research reactivity, researchers may try to make their data gathering efforts less conspicuous and intrusive without deception. For example, video-recorders may be concealed or employed more discretely with knowledge of the participants. Researchers conducting participantobservation may choose at times to act less as a 'participant' and more as an 'observer' to minimize reactivity. Junker (1960) describes a continuum of degrees of engagement that ranges from complete participant to observer as participant to participant as observer and to complete observer. Remaining mindful regarding the potential impacts research procedures can have on the findings is an important part of conceptualizing a qualitative research study.

In addition to reactivity, qualitative researchers manage the threat of researcher bias as they seek to achieve credibility. To manage such bias, researchers engage in reflexivity and seek to build self-awareness regarding their own influence on the research project (Drisko, 1997). Reflexivity is defined by Horsburgh (2003) as "active acknowledgement by the researcher that her/his own actions and decisions will inevitably impact upon the meaning and context of the experience under investigation” (p. 308). Reflexivity involves a thoughtful consideration of one's standpoint through reflection that may occur through keeping a written journal and engaging in dialog with peers (Johnson \& Waterfield, 2004). Lietz and colleagues (2006) conducted a study that analyzed autobiographical accounts regarding Jewish identity. The researchers describe extensive efforts to remain reflexive. Specifically, a journal was kept during the analysis process that recorded the analysts reactions to what was being read. In addition, the research team met and engaged in lengthy debates about how the differences in spiritual identity within the research team brought diverse perspectives of the transcripts. Ultimately, the journal and meetings 
brought a spirit of openness and accountability to the research process that the authors found highly important to their ability to offer a credible portrayal of the qualitative data.

Reflexivity is not an activity that occurs at one point in time, but instead represents a process that unfolds throughout the entire research process (Guillemin \& Gillam, 2004). Evidence of reflexivity may be discussed in the methods section of an article. Some authors may also include a statement of self disclosure where the researchers acknowledge their own bias and report their potential influence on the findings. Reflexivity is a critical part of managing research reactivity and bias and should be evident in the research article. Creswell and Miller (2000) suggest this is particularly relevant for studies stemming from a critical paradigm, although we contend reflexivity is an appropriate strategy to enhance trustworthiness in any qualitative research regardless of approach.

Other strategies to increase credibility include triangulation, member checking, and thick descriptions. Padgett (2008) defines triangulation as a concept adapted from navigational science involving the use of "two or more sources to achieve a comprehensive picture of a fixed point of reference” (p. 186). By gathering data from multiple sources (data triangulation) or utilizing multiple analysts to review the data (observer triangulation), qualitative researchers are able to achieve what Drisko (1997) refers to as "completeness" or an exhaustive response to the research question. Data triangulation might involve gathering data at multiple points in time or using varied data collection strategies such as interviews, focus groups, or observations (Creswell \& Miller, 2000). Triangulation by observer involves having more than one researcher analyze the data to be sure important ideas are not missed and that there is some consistency to how data analysis is linked to the findings. Some projects may involve multiple observers and interviewers working independently to collect the same type of data. For projects stemming from a post-positivist perspective, training should be provided to standardize their approach and minimize bias and variability in the way data is collected. Having a list of guiding questions, for example, helps to focus the observations of multiple observers in recording the phenomenon of interest. Padgett (2008) suggests that triangulation is particularly relevant with case studies and grounded-theory approaches, including mixed method studies (methodological triangulation).

When performing certain qualitative data analyses, such as content analysis, it may also be important to compute the intra- or inter-rater reliability of coders or analysts (Shek, Tang \& Han, 2005). Particularly studies coming from the post-positivist perspective prioritize the use of systematic procedures (Creswell \& Miller, 2000). However, for qualitative traditions which assert reality is constructed intersubjectively, computing inter-rater reliability is not consistent with the philosophical underpinnings of this position. When evaluating qualitative research, it is important to remember that credibility stems from the "intended inquiry purposes;" thus credible research decisions are consistent with one's purpose (Patton, 2002, p. 266), requiring practitioners to think critically and contextually when judging methodological decision making.

Member checking involves corroborating the research findings by seeking feedback from the research participants (Creswell \& Miller, 2000; Padgett, 2008). Member 
checking can involve including selected research participants in the data analysis or returning to a sample of participants with a draft of the findings to ascertain their sense of agreement with the findings (Shenton, 2004). For example, a researcher interested in resilience may interview adults who grew up in high risk circumstances to understand how some individuals come to cope effectively with adversity over time. The research team may identify a subset of their sample to provide feedback about the analysis. These individuals are provided a description of the preliminary analysis and are encouraged to offer feedback regarding whether the findings appear to reflect their own experiences. In some cases, specific questions may be used to guide this discussion when the researchers are seeking to clarify the meaning of certain quotes or accounts.

While some identify member checking to be one of the most valuable strategies for increasing trustworthiness in qualitative research (Lincoln \& Guba, 1985; Lietz et al., 2006), others acknowledge that member checking can raise practical concerns such as not being able to locate research participants or assuming that a sample of members' experiences are similar enough that they will all agree to the findings (Padgett, 2008). Despite these concerns, member checking is particularly important for studies stemming from the critical paradigm as these studies seek collaboration and corroboration with research participants (Creswell \& Miller, 2000).

The notion of thick description derives from the tradition of interpretive ethnography in anthropology, and involves "deep, dense, detailed accounts" of a phenomenon of inquiry with particular consideration of the context(s) in which it occurs (Denzin, 1989, p. 83). According to Geertz (1975), cultures are "webs of significance” and their analysis involves "an interpretive one in search of meaning" (p. 5). In this tradition, to adequately study a phenomenon, it is important to obtain ample and contextual documentation from which to derive knowledgeable and insightful interpretations. Specifically, Creswell and Miller (2000) explain:

The purpose of thick description is that it creates verisimilitude, statements that produce for the readers the feelings that they have experienced, or could experience, the events being described in a study. Thus credibility is established through the lens of readers who read a narrative account, and are transported into a setting or situation (p. 128-129).

Thick description is deemed particularly significant in constructivist research and in ethnographic studies. However, adequate description of the context and research procedures is relevant for qualitative research regardless of paradigmatic positions.

One strategy used to support the process of obtaining thick descriptions includes prolonged engagement. This involves conducting multiple interviews or spending extended time observing participants to achieve a complete look at the experience (Lincoln \& Guba, 1986). While seeking to establish credibility, researchers may document the training of interviewers or observers, the frequency, duration, and intensity of data collection efforts, probing techniques, whether interviews were audio-recorded or notes were taken, and whether data saturation was achieved. Ample use and discussion of examples of thematic findings is also helpful. Although many journals cannot 
accommodate lengthy descriptions, it remains the author's responsibility to adequately describe efforts taken to thoroughly account for the participants' experiences.

\section{Transferability}

Transferability refers to the degree to which the findings are applicable or useful to theory, practice and future research (Lincoln \& Guba, 1985). Sandelowski (1986) refers to this concept as "fittingness" suggesting transferability has to do with the degree to which findings fit situations outside of the study and are found meaningful. Qualitative research studies are not generalizable according to quantitative standards, because probability sampling is not employed. Instead, qualitative studies typically use purposive sampling to seek a specific group of participants who have experienced the phenomenon being studied. The number of research participants is typically smaller than quantitative studies, because as researchers seek to study experiences in-depth, the quality and exhaustive nature of each case becomes more important than the number of participants (Polkinghorne, 1995). In addition, constructivists challenge the relevance of generalizability in qualitative research, "arguing that an emphasis on generalizing strips away the context that imbues a qualitative study with credibility” (Padgett, 2008, p. 182).

Although qualitative researchers do not seek generalizability, transferability is achieved when the findings have applicability to another setting, to theory, to practice, or to future research. Devers (1999) suggests for findings to achieve transferability, “...the contexts must be similar. Therefore, it is the role of the researcher to identify key aspects of the context from which the findings emerge and the extent to which they may be applicable to other contexts" (p. 1165). Therefore, as researchers seek to achieve transferability, thick descriptions are again relevant allowing readers to understand ways findings may be applicable to other settings (Creswell \& Miller, 2000; Lincoln \& Guba, 1986; Shenton, 2004). The study's context should be described in detail and should relate to the context of other groups or settings (Devers, 1999). For example, in a current study, Zayas and colleagues are documenting the challenges that quality assurance professionals experienced in performing their functions in community-based behavioral health agencies. These study findings along with the suggestions that followed may be applicable in and transferable to other community agencies that provide similar services with comparable staff, resources, and clientele.

Finally, when assessing transferability, credibility is again important. Just as a study that produces reliable, but invalid data is not useful in quantitative research, qualitative studies that produce transferable findings that are not credible do not contribute to the knowledgebase.

\section{Auditability}

Lincoln and Guba (1985) identify the third criteria for evaluating qualitative research projects as auditability. Auditability refers to the degree to which research procedures are documented allowing someone outside the project to follow and critique the research process (Padgett, 2008). While quantitative research requires strict adherence to study procedures, qualitative methodology does allow for some flexibility. In fact, some 
suggest high quality projects should demonstrate an iterative process that changes as the study unfolds (Davies \& Dodd, 2002; Drisko, 1997; Frankel, 1999; Morrow, 2007). For example, interview instruments may be revised during early stages of data collection if questions are not yielding quality information. Proposed sample sizes may be increased or decreased based on data saturation. Also, codebook development involves painstaking deliberations among analysts based on their assessment of a certain number and type of data sources. When, why and how are such consequential decisions made? One way of addressing the need to make decisions and changes along the way is to provide detailed documentation throughout the research project. Projects stemming from a post-positivist perspective will commonly prioritize systematic procedures such as these (Creswell \& Miller, 2000). However, we contend keeping an account of the research procedures and decisions seems relevant for all approaches.

The strategies used to increase auditability include keeping an audit trail and engaging in peer debriefing. An audit trail is a written account of the research process that includes a reporting of what occurred throughout the research project along with a demonstration of reflexivity. Mullins, Cheung, and Lietz (under review) recently conducted a project that involved describing families' descriptions of family preservation services. In this project, the authors chose to maintain the audit trail through Google Docs. This document included detailed accounts of each research meeting, the research decisions that were made throughout the process, and each member's reactions after engaging in any coding of the transcripts. By using an online document, any member of the team was able to go into and add to the document at any time, providing an efficient way to maintain a detailed account of the project from beginning to end. Although a copy or excerpts from the audit trail are rarely included in the research article, many authors will report the maintenance of an audit trail to demonstrate auditability. It can help to clarify concerns and increase the confidence of other researchers and reviewers about the conduct of the study.

Additionally, peer debriefing involves consulting with colleagues experienced in qualitative methodology (Padgett, 2008). By discussing research decisions and procedures, important feedback can be provided enhancing the quality of the project (Shenton, 2004). Peer debriefing can help to promote reflexivity allowing researchers to become more sensitized to the effects of their socio-political position. It can also enhance the research process by generating new ideas and identifying potential pitfalls related to the methodology. For example, in the study referenced earlier of Jewish identity (Lietz et al., 2006), the researcher engaged in the analysis of these autobiographical accounts did not personally identify with this spiritual tradition. In order to increase reflexivity and accountability, a decision was made to consult with another qualitative researcher who was Jewish to provide an insider's perspective to the data analysis process.

An audit trail is of particular relevance for post-positivist qualitative research while peer debriefing is seen by some as necessary for projects stemming from a critical standpoint (Creswell \& Miller, 2000). However, some suggest that peer debriefing and auditing may represent “...potentially contaminating influences that interfere with the search for deep structures of meaning” in phenomenological approaches (Padgett, 2008, 
p. 194). In other words, these approaches are divorced from the lived experience, possibly leading the researchers away from their intimate interaction with data.

\section{Confirmability}

Confirmability refers to the ability of others to confirm or corroborate the findings (Drisko, 1997; Lincoln \& Guba, 1985). Shenton (2004) asserts "steps must be taken to help ensure as far as possible that the work's findings are the result of the experiences and ideas of the informants, rather than the characteristics and preferences of the researcher” (p. 72). To achieve confirmability, a study demonstrates that the findings and data are clearly linked. There are several strategies that a researcher can use to increase a study's confirmability. Already discussed were the benefits of member checking, peer debriefing, and audit trails. These strategies allow collaborators external to the research team an opportunity to evaluate or confirm the research procedures.

In addition, negative case analysis is a strategy used when a researcher deliberately seeks contrasting evidence, a strategy commonly employed in a grounded theory approach (Padgett, 2008). Frankel (1999) suggests looking at "deviant cases" is "perhaps most important" when determining whether the qualitative researcher achieved an adequate look at the research question (p. 344). An example might include a researcher who is exploring diverse perspectives regarding immigration policy. If the sample included a group of citizens who favored a particular policy position, negative case analysis would require a researcher to continue recruitment into the study until alternative or contrasting perspectives were represented in the findings. Negative case analysis is relevant not just during sampling but also throughout data analysis. It requires that analysts seek disconfirming evidence when analyzing their qualitative data. Creswell and Miller (2000) note that this strategy is especially useful for constructivist research. Drisko (1997) suggests seeking contradictory evidence and diverse experiences is essential to achieving a complete or exhaustive exploration of a phenomenon.

Table 1 provides a summary of research strategies available to increase the trustworthiness of a qualitative research project. Notwithstanding, no project is expected to employ all of these strategies. There may be some projects where triangulation seems particularly relevant, such as mixed-methods studies, whereas member checking may be critical in another, such as participatory inquiry. As one evaluates the quality of a qualitative project, while it is not necessary or even appropriate for a researcher to engage in all of the strategies provided in Table 1, there should be evidence that the researcher addressed research reactivity/bias and enhanced credibility, transferability, auditability, and confirmability in accordance with the paradigmatic lens of the project (Creswell \& Miller, 2000). 
Table 1. Research Strategies for Increasing Trustworthiness of Qualitative Research

Reflexivity

Observer Triangulation

Data Triangulation

Prolonged Engagement

Member Checking

Thick Descriptions

Audit Trail

Peer Debriefing

Negative Case Analysis
A thoughtful consideration of how a researcher's standpoint can influence the research.

Using more than one researcher to analyze the data.

Collecting data from multiple sources such as interviews, focus groups and interviews.

Conducting multiple interviews or spending extended time with participants to achieve an exhaustive look at the experience.

Including participants in analysis or returning to a sample of participants to corroborate the findings.

A thorough representation of the phenomenon of inquiry and its context as perceived and experienced by study participants.

Keeping a detailed written account of the research procedures.

Meeting with mentors or other researchers engaged in qualitative research to dialogue regarding research decisions.

Seeking contrasting evidence through sampling and analysis.

Sources: Lincoln and Guba (1985); Padgett (2008); Shenton (2004)

\section{EVALUATING QUALITATIVE RESEARCH FOR PRACTITIONERS}

When evaluating qualitative research, Lincoln and Guba (1985) suggest researchers plan and conduct their studies seeking to achieve trustworthiness. Trustworthiness is evaluated according to the degree to which the study is credible, transferable, auditable and confirmable. Table 1 summarizes ten strategies researchers can use to increase the quality of their qualitative studies and Table 2 provides a list of questions practitioners may ask to determine a study's trustworthiness. Important to remember is that not all strategies need to be utilized for a study to be trustworthy. It is for the reader to determine whether the strategies chosen align with the purpose, epistemological positioning, and design of the project, and whether they adequately manage threats to research reactivity and bias. In addition, evaluators of qualitative research articles should remain mindful of the impacts of these threats on both data collection and the analysis of the data. Regardless of how rigorous data analysis strategies are, data collection procedures must first collect data that are authentic and as exhaustive as possible, taking a comprehensive look at an experience in spatio-temporal context. Once a researcher has established that 
data are "thick" and complete, strategies are once again taken to ensure that analytic processes lead to an accurate representation of the participants' perspectives.

Table 2. Questions Practitioners Can Ask to Evaluate Trustworthiness of Qualitative Research Articles

$\checkmark$ Did the research study identify a paradigmatic lens or research tradition in the article?

$\checkmark$ If there was no tradition, were the purpose and epistemological positions made clear?

$\checkmark$ Were the methods consistent with the tradition and/or purpose?

$\checkmark$ How was research reactivity and bias managed in the study?

$\checkmark$ What strategies were used to establish the credibility?

$\checkmark$ How extensive or 'thick' were the descriptions supporting findings? Was the context adequately described?

$\checkmark$ Were the findings applicable or useful for your population, setting or area of practice?

$\checkmark$ Was there evidence of an audit trail and/or peer consultation on the project?

$\checkmark$ How did the researchers corroborate their conclusions?

$\checkmark$ To what degree do you find the research procedures increased the trustworthiness of the findings?

Considering heightened expectations that social work practitioners are able to identify, evaluate, and use research in their practice, knowledge of research procedures has become an essential part of being a social work practitioner. Rigorous qualitative research can offer important implications for social work practice. The purpose of this article is to provide social workers some concepts to help frame their evaluation of the trustworthiness of qualitative research. As practitioners become more confident regarding their understanding of qualitative methods, they can better ascertain the applicability or usefulness of qualitative studies in their practice settings.

\section{References}

Adams, K. B., Matto, H. C., \& LeCroy, C. W. (2009). Limitations of evidence-based practice for social work education: Unpacking the complexity. Journal of Social Work Education, 45(2), 1-22.

Bogdan, R. C., \& Biklen, S. K. (2007). Qualitative research for education: An introduction to theories and methods. Needham Heights, MA: Allyn \& Bacon.

Caelli, K., Ray, L., \& Mill, J. (2003). Clear as mud: Toward greater clarity in generic qualitative research. International Journal of Qualitative Methods, 2(2), Article 1. Retrieved from http://www.ualberta.ca/ iiqm/backissues/pdf/caellietal.pdf 
Creswell, J. W. (1998). Qualitative inquiry and research design: Choosing among five traditions. Thousand Oaks, CA: Sage Publications.

Creswell, J. W. (2008). Research design: Qualitative, quantitative, and mixed methods approaches. Thousand Oaks, CA: Sage Publications.

Creswell, J. W., \& Miller, D. L. (2000). Determining validity in qualitative inquiry. Theory Into Practice, 39(3), 124-130.

Davies, D., \& Dodd, J. (2002). Qualitative research and the question of rigor. Qualitative Health Research, 12(2), 279-289.

Denzin, N. K. (1989). Interpretive interactionism. Newbury Park, CA: Sage Publications.

Denzin, N. K., \& Lincoln, Y. S. (2008). Collecting and interpreting qualitative materials. Los Angeles: Sage Publications.

DePoy, E., Hartman, A., \& Haslett, D. (1999). Critical action research: A model for social work knowing. Social Work, 44(6), 560-569.

Devers, K. J. (1999). How will we know "good" qualitative research when we see it? Beginning the dialogue in health services research. Health Services Research 34(5), 1153-1188.

Drisko, J. W. (1997). Strengthening qualitative studies and reports: Standards to promote academic integrity. Journal of Social Work Education, 33(1), 185-197.

Drisko, J. W. (2008). How is qualitative research taught at the master's level? Journal of Social Work Education, 44(1), 85-101.

Emden, C., \& Sandelowski, M. (1998). The good, the bad and the relative, part one: Conceptions of goodness in qualitative research. International Journal of Nursing Practice, 4, 206-212.

Emden, C., \& Sandelowski, M. (1999). The good, the bad and the relative, part two: Goodness and the criterion problem in qualitative research. International Journal of Nursing Practice, 4, 2-7.

Frankel, R. (1999). Standards of qualitative research. In B. Crabtree\& W. Miller(Eds.), Doing qualitative research ( $2^{\text {nd }}$ ed., pp. 333-346). Los Angeles: Sage Publications.

Gambrill, E. (2007). Social workers' code of ethics and accreditation standards as guides for choice. Journal of Social Work Education, 43(3), 447-462.

Geertz, C. (1975). The interpretation of cultures: Selected essays. London: Hutchinson.

Gilgun, J. (2005). The four cornerstones of evidence-based practice in social work. Research on Social Work Practice, 15(1), 52-61.

Guillemin, M., \& Gillam, L. (2004). Ethics, reflexivity, and 'ethically important moments' in research. Qualitative Inquiry, 10(2), 261-280. 
Holloway, S., Black, P., Hoffman, K., \& Pierce, D. (2009). Some Considerations of the Import of the 2008 EPAS for Curriculum Design. Retrieved from http://www.cswe.org/CSWE/accreditation/200906+CompetencyPractice+Behavior.htm

Horsburgh, D. (2003). Evaluation of qualitative research. Journal of Clinical Nursing, 12, 307-312.

Howard, M., McMillen, C., \& Pollio, D. (2003). Teaching evidence-based practice: Toward a new paradigm for social work education. Research on Social Work Practice, 13(2), 234-259.

Jenson, J. (2005). Connecting science to intervention: Advances, challenges, and the promise of evidence-based practice. Social Work Research, 29(3), 131-135.

Johnson, R., \& Waterfield, J. (2004). Making words count: the value of qualitative research. Physiotherapy Research International, 9(3), 121-131.

Junker, B. H. (1960). Field work: An introduction to the social sciences. Chicago: University of Chicago Press.

Kincheloe, J. (2001). Describing the bricolage: Conceptualizing a new rigor in qualitative research. Qualitative Inquiry, 7(6), 679-692.

Lietz, C. A., Langer, C., \& Furman, R. (2006). Establishing trustworthiness in social work research: Implications from a study regarding spirituality. Qualitative Social Work, 5(4), 441-458.

Lincoln, Y., \& Guba, E. (1985). Naturalistic inquiry. Beverly Hills, CA: Sage.

Lincoln, Y., \& Guba, E. (1986). But is it rigorous? Trustworthiness and authenticity in naturalistic evaluation. New Directions for Program Evaluation, 20, 15-25.

McNeece, C. A., \& Thyer, B. (2004). Evidence-based practice and social work. Journal of Evidence-Based Social Work, 1(1), 7-25.

Morrow, S. (2007). Qualitative research in counseling psychology: Conceptual foundations. The Counseling Psychologist, 35(2), 209-235.

National Association of Social Workers. (NASW). (1999). Code of ethics. Washington, DC: NASW Press.

Olesen, V. L. (2000). Feminisms and qualitative research at and into the millennium. In N. K. Denzin \& Y. S. Lincoln (Eds.), Handbook of qualitative research $\left(2^{\text {nd }}\right.$ ed., pp. 215-255). Thousand Oaks, CA: Sage.

Padgett, D. (2008). Qualitative methods in social work research. Los Angeles: Sage Publications.

Patton, M. Q. (2002). Two decades of developments of qualitative inquiry: A personal, experiential perspective. Qualitative Social Work, 1(3), 261- 283.

Polkinghorne, D. E. (1995). Narrative configuration in qualitative analysis. Qualitative Studies in Education, 8(1), 5-23. 
Rubin, A., \& Babbie, E. (2010). Research methods for social work. Belmont, CA: Cengage/Brooks \& Cole.

Sandelowski, M. (1986). The problem of rigor in qualitative research. Advances in Nursing Science, 8(3), 27-37.

Shek, D., Tang, V., \& Han, X. (2005). Evaluation of evaluation studies using qualitative research methods in social work literature (1990-2003): Evidence that constitutes a wake-up call. Research on Social Work Practice, 15(3), 180-194.

Shenton, A. (2004). Strategies for ensuring trustworthiness in qualitative research projects. Education for Information, 22, 63-75.

Whittemore, R., Chase, S., \& Mandle, C. (2001). Validity in qualitative research. Qualitative Health Research, 11(4), 522-537.

\section{Author's note:}

Address correspondence to: Cynthia A. Lietz, School of Social Work, Arizona State University, 411 N. Central Ave, Suite 800, Phoenix, AZ, 85004-0689. Email:

clietz@asu.edu 